\title{
THE TIME Has COME FOR SPEECH-LANGUAGE PATHOLOGY LICENSE PORTABILITY!
}

\author{
MELISSA JAKUBOWITZ, MA, CCC-SLP \\ PRESENCELEARNING, SAN FRANCISCO, CA
}

\section{ABSTRACT}

Melissa Jakubowitz, M.A., CCC-SLP is Vice President of SLP Services at PresenceLearning. A speech-language pathologist with over 20 years of clinical and managerial experience, Ms. Jakubowitz is a Board Recognized Specialist in Child Language. With a diverse clinical background, Ms. Jakubowitz began her career working in the public schools and has also operated a successful, multi-office private practice. She is a past Director of the Scottish Rite Institute for Childhood Language Disorders in Stockton, CA. She is also a past-president of the California Speech-Language-Hearing Association, which, with over 5,000 SLP members, is one of the largest speech-language pathologist state associations in the country. Active in the American Speech-Language-Hearing Association (ASHA), Ms. Jakubowitz served as a Legislative Counselor for 12 years.

Keywords: Telepractice, personnel shortages, license portability, speech-language pathology

Over the past decade, a chronic shortage of speechlanguage pathologists has left K-12 schools and healthcare settings in many parts of the United States struggling to provide speech therapy services. The problem has taken a financial toll, driving the cost of services up as institutions spend increasing time and funds searching for speech-language pathologists.

Telepractice offers a promising solution by enabling practitioners to conduct live therapy sessions with clients "anytime, anywhere" using real-time videoconferencing. Telepractice allows practitioners to flexibly "go where the work is" without actually having to physically travel or relocate. Speech-language pathologists who no longer engage in full-time practice but still wish to work parttime, can contract with school districts to provide speech therapy services via telepractice. Ultimately, telepractice addresses a labor problem that impacts many health professions.

This cost-effective approach is being successfully employed by school districts across the United States, reducing costs while providing high-quality therapy. Research indicates that speech therapy delivered through telepractice has comparable quality and outcomes as speech therapy services delivered in-person (American Speech-Language-Hearing Association, 2005; Boisvert, Lang, Andrianopoulos, \& Boscardin, 2010; Boswell, 2007; Grogan-Johnson, Alvares, Rowan \& Creaghead, 2010; Grogan-Johson et al., 2011).
Although technology has removed geographic constraints, one major barrier remains: time consuming and expensive licensing practices due to a lack of state license portability. While the professional requirements for licensing speech-language pathologists are very similar from state to state, each state has its own licensing process. As a result, speech-language pathologists who want to practice in multiple states must complete applications in each state where a license is sought; submit required documentation; pay licensing fees; and, endure processing times that significantly vary by state. This duplicative process might be warranted if important state-to-state variations in professional requirements for licensing were to exist; however, there is a high degree of consistency in licensing requirements across states.

Though the professional requirements are typically similar, license application processing times and fees vary by state. Some states process applications electronically, while others use a paper-based format. Depending on the state, the processing times for applications range from weeks to months. All states charge licensing application fees (typically $\$ 150$ and higher) for the initial application, with similar charges for annual license renewal. In some states, licensees must provide fingerprints along with their license application. States do not share fingerprint information; applicants must send fingerprints to the state where the license is requested through an approved process. 
The importance of licensure portability was recognized fifteen years ago when the United States Congress passed the Telecommunications Act of 1996 which urged the healthcare industry to develop multi-state licensure models. Similarly, the US Federal Communications Commission called on state licensing boards to accommodate multi-state licensure for health care practitioners. In 2000, the National Council of State Boards of Nursing (NCSBN) instituted the Nurse License Compact (NLC). The NLC allows nurses licensed in a compact state (currently 24 states) to practice in other compact states through a mutual license recognition model. Physicians have labor mobility through an expedited license model.

True license portability for speech-language pathologists is long overdue. License portability would facilitate inter-state practice and thus enable speechlanguage pathologists who live near state lines to practice in adjacent states where personnel shortages may exist. Greater labor mobility is necessary to serve geographically shifting populations in the US.

It is time to remove the barriers to licensure portability! A national initiative that creates a model for licensure portability for the rehabilitation professions is needed. Licensure portability will enable speech-language pathologists to provide services wherever and whenever needed, thereby unleashing the full potential of telepractice to reduce costs and administrative burdens, increase access to services, broaden career opportunities for speech-language pathologists and improve outcomes for K-12 students and clients in diverse practice settings. A mobile, flexible workforce positioned to use telepractice for inter-state practice could alleviate the chronic shortage of speech-language pathologists.

\section{REFERENCES}

1. American Speech-Language-Hearing Association. (2005). Speech-Language Pathologists Providing Clinical Services via Telepractice: Position Statement [Position Statement]. Retrieved from www.asha.org/policy.

2. Boisvert, M., Lang, R., Andrianopoulos, M., \& Boscardin, M. (2010). Telepractice in the assessment and treatment of individuals with autism spectrum disorders: A systematic review. Developmental Neurorehabilitation, 13, 423-432.

3. Boswell, S. (2007, March 6). Ohio grant addresses personnel shortage: Innovative strategies meet shortand long-term goals. The ASHA Leader.

4. Grogan-Johnson, S., Alvares, R., Rowan, L. E., \& Creaghead, N. (2010). A pilot study comparing the effectiveness of speech-language intervention provided by telehealth and traditional side-by-side intervention. Journal of Telemedicine and Telecare, 16, 134-139.

5. Grogan-Johnson, S., Gabel, R., Taylor, J., Rowan, L., Alvares, R., \& Schenker, J. (2011). A pilot exploration of speech sound disorder intervention delivered by telehealth to school-age children. International Journal of Telerehabilitation, 3(1), 31-42. 
INTERNATIONAL JOURNAL OF TELEREHABILITATION · TELEREHAB.PITT.EDU $\coprod$ 
